\title{
POSSIBILIDADES E DESAFIOS DA EDUCAÇÃO FÍSICA COMO COMPONENTE CURRICULAR NO PROCESSO DE EXPANSÃO REGIONAL DO INSTITUTO FEDERAL DE EDUCAÇÃO, CIÊNCIA E TECNOLOGIA DO RIO GRANDE DO NORTE - IFRN
}

\author{
A. P. BATISTA' ${ }^{1}$, M. SOUZA FILHO ${ }^{1}$, I. P. B. OLIVEIRA' ${ }^{1}$, H. A. G. SOUZA ${ }^{2}$ e J. P. MELO \\ ${ }^{1}$ Instituto Federal do Rio Grande do Norte \\ ${ }^{3}$ Universidade Federal do Rio Grande do Norte \\ ${ }^{2}$ Universidade Estadual do Rio Grande do Norte \\ alison.batista@ifrn.edu.br
}

Artigo submetido em fevereiro/2014 e aceito em agosto/2014

DOI: $10.15628 /$ holos.2014.2018

\begin{abstract}
RESUMO
O presente escrito constitui-se de uma reflexão teórica originada e motivada durante os estudos de pósgraduação desenvolvidos pelos seus autores. Durante o desenvolvimento de nossas pesquisas, sentimo-nos instigados a relacionar os nossos investimentos acadêmicos, com o nosso fazer pedagógico institucional. Além disso, tivemos como fonte de motivação a comemoração alusiva aos cinco anos de criação dos Institutos Federais no Brasil. Nesse sentido, tivemos como objetivo principal discutir a relevância sociocultural do IFRN, assim como a função social da Educação Física como componente curricular no processo de formação do ensino médio integrado. Para tanto, baseamo-nos nas leis de diretrizes e bases da educação nacional - LDBEN no
\end{abstract}

9.394/96 e 11.892, como também em documentos institucionais, tais como o Projeto Político Pedagógico do IFRN e a Proposta de trabalho do componente curricular Educação Física. Assim sendo, a contribuição da Educação Física no âmbito do IFRN poderá se concretizar à medida em que o corpo docente, que desenvolve as ações pedagógicas do componente curricular, realize e socialize as experiências pedagógicas contextualizadas com a função social do IFRN na dimensão da formação integrada, considerando a cultura de movimento como o conjunto de conhecimentos relativos aos conteúdos temáticos como pressupostos teórico-metodológicos da proposta pedagógica.

PALAVRAS-CHAVE: Educação profissionalizante; Educação Física; Componente Curricular; Proposta Pedagógica.

\section{POSSIBILITIES AND CHALLENGES OF PHYSICAL EDUCATION CURRICULUM COMPONENT IN THE PROCESS OF REGIONAL EXPANSION OF FEDERAL INSTITUTE OF EDUCATION, SCIENCE AND TECHNOLOGY OF THE RIO GRANDE DO NORTE - IFRN}

\begin{abstract}
$O$ This writing constitutes a theoretical reflection originated and motivated during graduate studies developed by the authors. During the development of our research, we feel encouraged to relate our academic investments with our institutional pedagogical practice. Furthermore, we as a source of motivation celebrating alluding to the five breeding years in federal institutes in Brazil. In this sense, we had as main objective to discuss the relevance of sociocultural IFRN, as well as the social function of Physical Education as a curriculum component in the formation of integrated high school process. For this, we rely on the laws and guidelines of national education bases - LDBEN No. 9.394/96 and
\end{abstract}

11,892 , as well as in institutional documents Politico IFRN the Pedagogical Project Proposal and Work of Physical Education curriculum component. In this sense, the contribution of physical education within the IFRN can be realized as the faculty which develops the pedagogical actions of the curricular component, perform and socialize the contextualized learning experiences with the social function of the dimension of IFRN integrated training considering the movement culture as a set of knowledge related to the thematic content of the theoretical assumptions and methodological educational proposal.

KEYWORDS: Vocational education; Physical Education; Curriculum Component; Pedagogical Proposal. 


\section{DESVELANDO AS AÇÕES DO IFRN EM NOSSO ESTADO}

A função social do IFRN é ofertar Educação Profissional e tecnológica - de qualidade referenciada socialmente e de arquitetura político-pedagógica capaz de articular ciência, cultura, trabalho e tecnologia - comprometida com a formação humana integral, com o exercício da cidadania e com a produção e a socialização do conhecimento, visando, sobretudo, à transformação da realidade na perspectiva da igualdade e da justiça sociais. Desse modo, o IFRN contribui para uma formação omnilateral que favorece, nos mais variados âmbitos, o (re)dimensionamento qualitativo da práxis social (IFRN, PPP, 2012, p.8).

Refletir sobre o compromisso social e o papel do Instituto Federal de Educação, Ciência e Tecnologia do Rio Grande do Norte - IFRN no âmbito da educação é uma tarefa instigante e desafiadora. Tal proposição decorre, inevitavelmente, por estarmos inseridos nesta casa de educação na condição de docentes, como também pelo desejo de contextualizar os nossos investimentos acadêmicos com o nosso fazer pedagógico. Nesse sentido, as reflexões que tecemos ao longo deste escrito objetivam, principalmente, discutir a relevância sociocultural do IFRN, assim como a função social da Educação Física como componente curricular no processo de formação do ensino médio integrado. Desse modo, foi imprescindível para a construção deste escrito a leitura prévia de algumas leis que regem a educação e os Institutos Federais em nosso país, tais como a Lei da Educação Nacional - LDBEN no 9.394/96 e a lei $11.892^{1}$, como também dos principais documentos institucionais (Projeto Político e Pedagógico e a sua Organização Didática), considerados pilares organizacionais da nova configuração e que normatizam e regulamentam o funcionamento do IFRN enquanto uma instituição de educação profissional por vocação, com a inclusão de várias modalidades de ensino.

Além desses documentos, levamos em consideração algumas diretrizes produzidas pelo MEC, que foram de suma importância para a organização teórica e metodológica da Educação Física nos últimos anos para o ensino médio, como por exemplo os Parâmetros Curriculares Nacionais - PCNs (2000), os PCNs+ (2002) e as Orientações Curriculares Nacionais - OCEM (2012). Atrelado a todo esse acervo teórico, procuramos inserir em nossa análise as contribuições de autores que vêm discutindo novas perspectivas pedagógicas em prol da construção de uma Educação Física mais fundamentada e coerente com a escola da atualidade.

Embora a denominação IFRN tenha sido estabelecida em 2008 pela lei 11.892, queremos evidenciar a nossa compreensão de que esta casa de educação é uma instituição centenária, pois sua história se inicia no Rio Grande do Norte em 1909, como uma Escola de Aprendizes Artífices. Durante o decorrer dos anos, a instituição tem passado por várias modificações, sendo denominada sequencialmente por Liceu Industrial de Natal em 1937 e, a partir de 1942, passando a ser denominada de Escola Industrial de Natal (EIN). No ano de 1965, esta instituição passou a ser chamada de Escola Industrial Federal do Rio Grande do Norte (EIFRN), sendo denominada,

\footnotetext{
${ }^{1}$ A Lei 11.892, publicada em 29/12/2008, cria no âmbito do Ministério da Educação um novo modelo de instituição de educação profissional e tecnológica. Estruturados a partir do potencial instalado nos Cefet, escolas técnicas e agrotécnicas federais e escolas vinculadas às universidades federais, os novos Institutos Federais de Educação, Ciência e Tecnologia geram e fortalecem condições estruturais necessárias ao desenvolvimento educacional e socioeconômico brasileiro.
} 
posteriormente, por uma Portaria Ministerial de 1968, de Escola Técnica Federal do Rio Grande do Norte (ETFRN). Passados alguns anos, ocorreu novamente um processo de reestruturação da rede federal de ensino técnico profissionalizante, alterando, mais uma vez, a nomenclatura desta instituição para Centro Federal de Educação Tecnológica do Rio Grande do Norte (CEFET-RN), no ano de 1999.

Considerando a relevância desse percurso histórico institucional, fizemos um recorte temporal em nosso estudo e centramos a nossa reflexão a partir da lei 11.892 , que criou os Institutos Federais (IF'S). Essa lei foi promulgada pelo presidente Luiz Inácio Lula da Silva, em 29 de dezembro de 2008. De acordo com o que consta em seu Capítulo I, Art. 2으,

Os Institutos Federais são instituições de educação superior, básica e profissional, pluricurriculares e multicampi, especializados na oferta de educação profissional e tecnológica nas diferentes modalidades de ensino, com base na conjugação de conhecimentos técnicos e tecnológicos com as suas práticas pedagógicas, nos termos desta Lei § 10 Para efeito da incidência das disposições que regem a regulação, avaliação e supervisão das instituições e dos cursos de educação superior, os Institutos Federais são equiparados às universidades federais.

Embora o IFRN esteja agora inserido no âmbito das Instituições de Ensino Superior, queremos destacar que as discussões nesta pesquisa perpassaram fundamentalmente pela educação básica, especificamente pelo ensino médio integrado. Desse modo, para que pudéssemos alavancar uma reflexão coesa sobre o contributo do IFRN para a comunidade estudantil e a sociedade norteriograndense, fez-se necessário conhecermos as finalidades, as características e os objetivos da criação dos IF'S, para que pudéssemos relacionar tais expectativas com a dinâmica atual de nossa sociedade.

Assim, segundo a Lei № 11.892 em seu Capítulo II, Art.6으, os IF'S têm por finalidade e características nove itens, a saber:

I - ofertar educação profissional e tecnológica, em todos os seus níveis e modalidades, formando e qualificando cidadãos com vistas na atuação profissional nos diversos setores da economia, com ênfase no desenvolvimento socioeconômico local, regional e nacional; II - desenvolver a educação profissional e tecnológica como processo educativo e investigativo de geração e adaptação de soluções técnicas e tecnológicas às demandas sociais e peculiaridades regionais; III - promover a integração e a verticalização da educação básica à educação profissional e educação superior, otimizando a infraestrutura física, os quadros de pessoal e os recursos de gestão; IV - orientar sua oferta formativa em benefício da consolidação e fortalecimento dos arranjos produtivos, sociais e culturais locais, identificados com base no mapeamento das potencialidades de desenvolvimento socioeconômico e cultural no âmbito de atuação do Instituto Federal; V constituir-se em centro de excelência na oferta do ensino de ciências, em geral, e de ciências aplicadas, em particular, estimulando o desenvolvimento de espírito crítico, voltado à investigação empírica; VI - qualificar-se como centro de referência no apoio à oferta do ensino de ciências nas instituições públicas de ensino, oferecendo capacitação técnica e atualização pedagógica aos docentes das redes públicas de ensino; VII - desenvolver programas de extensão e de divulgação científica e tecnológica; VIII - realizar e estimular a pesquisa aplicada, a produção cultural, o empreendedorismo, o cooperativismo e o desenvolvimento 
científico e tecnológico; IX - promover a produção, o desenvolvimento e a transferência de tecnologias sociais, notadamente as voltadas à preservação do meio ambiente.

Ao refletirmos a respeito dessas finalidades e sobre as características apresentadas pela referida lei, chegamos ao entendimento de que todas as proposições contemplam o ensino médio. Desse modo, até a finalidade elencada no item número VI (referente à atualização técnica dos docentes das redes públicas de ensino), que não está relacionada diretamente à educação básica, repercute diretamente no ensino médio, pois, ao participar de ações de capacitação e atualização de professores que atuam nesse nível de ensino, os IF'S poderão estar corroborando com ações voltadas ao desenvolvimento e à melhoria da educação pública do país.

No que tange aos objetivos estabelecidos pela referida lei de criação em seu Capítulo II, Art.7ํㅡㅇ os Institutos Federais têm como função primordial:

I - ministrar educação profissional técnica de nível médio, prioritariamente na forma de cursos integrados, para os concluintes do ensino fundamental e para o público da educação de jovens e adultos; II - ministrar cursos de formação inicial e continuada de trabalhadores, objetivando a capacitação, o aperfeiçoamento, a especialização e a atualização de profissionais, em todos os níveis de escolaridade, nas áreas da educação profissional e tecnológica; III - realizar pesquisas aplicadas, estimulando o desenvolvimento de soluções técnicas e tecnológicas, estendendo seus benefícios à comunidade; IV - desenvolver atividades de extensão de acordo com os princípios e finalidades da educação profissional e tecnológica, em articulação com o mundo do trabalho e os segmentos sociais, e com ênfase na produção, desenvolvimento e difusão de conhecimentos científicos e tecnológicos; $V$ - estimular e apoiar processos educativos que levem à geração de trabalho e renda e à emancipação do cidadão na perspectiva do desenvolvimento socioeconômico local e regional; e VI - ministrar em nível de educação superior: a) cursos superiores de tecnologia, visando à formação de profissionais para os diferentes setores da economia; b) cursos de licenciatura, bem como programas especiais de formação pedagógica, com vistas na formação de professores para a educação básica, sobretudo nas áreas de ciências e matemática, e para a educação profissional; c) cursos de bacharelado e engenharia, visando à formação de profissionais para os diferentes setores da economia e áreas do conhecimento; d) cursos de pós-graduação lato sensu de aperfeiçoamento e especialização, visando à formação de especialistas nas diferentes áreas do conhecimento; e e) cursos de pós-graduação stricto sensu de mestrado e doutorado, que contribuam para promover o estabelecimento de bases sólidas em educação, ciência e tecnologia, com vistas no processo de geração e inovação tecnológica.

A lei 11.892 e todas as ações governamentais advindas dela trouxeram inúmeros benefícios para a população brasileira, sendo considerada a expansão da rede de federal de ensino técnico e tecnológico como uma das principais ações políticas. No entanto, é premente destacar que essa lei federal atendeu a uma tendência/cobrança realizada por instituições internacionais, detentoras de capital como o Banco Mundial. Para Cabral Neto (2009, p. 27), de acordo com as diretrizes estabelecidas pelo Banco Mundial no ano 2000, "os países necessitam educar maior proporção de seus jovens em níveis mais altos, uma vez que, na atualidade, possuir grau universitário é requisito básico para muitos trabalhos especializados". 
Nessa perspectiva, o governo visualizou os Institutos Federais como instituições mistas (ensino médio e ensino superior) capazes de facilitar a construção dessa ponte entre a educação básica e o ensino superior, pois "o aumento do número de diplomados de nível médio suscita, também, o aumento de pessoas interessadas em ingressar na universidade, desafiando os governos a expandirem os investimentos no ensino superior" (IDEM). De acordo com o projeto Político Pedagógico-PPP do IFRN (2012), até o ano de 2005 a rede federal de educação profissional e tecnológica detinha apenas 140 escolas técnicas em todo o país. A partir dessa realidade, foi estimado pelo Plano de Desenvolvimento da Educação (PDE) de 2011 que até 2014 haveria um processo de expansão e interiorização dessa rede, que possibilitaria atingir o marco de aproximadamente 600 câmpus em todo o território nacional.

A expansão dos IF'S no Brasil foi bastante expressiva, sendo o Rio Grande do Norte um dos estados mais beneficiados com a ampliação da rede. O IFRN passou de cinco campi em 2008 (NatalCentral, Mossoró, Natal-Zona Norte, Ipanguassú e Currais Novos), para dezenove campi em 2013, sendo acrescidos os campi de Apodi, Caicó, João Câmara, Macau, Pau dos Ferros, Santa Cruz, NatalCidade Alta, Nova Cruz, Parnamirim, São Gonçalo do Amarante, EAD - Educação à Distância, São Paulo do Potengi, Ceará-Mirim e Canguaretama. A previsão de consolidação de expansão do IFRN em nosso estado está prevista para 2015 com a construção de mais dois campi (Parelhas e Lages), totalizando vinte e um campi no estado.

A ocupação do IFRN nas diversas regiões do estado tem contribuído, significativamente, para torná-lo uma instituição efetivamente de desenvolvimento econômico, regional e social, sendo a educação, a ciência e a tecnologia elementos centrais desse processo. Além disso, a amplitude territorial do IFRN tem contribuído para a construção e manutenção da respeitabilidade desta centenária instituição de ensino junto às comunidades em que os novos campi estão sendo inseridos, pois o ensino, a pesquisa e a extensão têm somado efetivamente para o desenvolvimento da função social do IFRN junto às diversas comunidades do estado (IFRN - PPP, 2012).

Na concepção do PPP do IFRN (2012, p.22), a expansão do IFRN pelo interior do estado,

[...] amplia, significativamente, a atuação nas áreas de ensino, de pesquisa e de extensão; contribui, de modo mais extensivo, para a formação humana e cidadã; e estimula o desenvolvimento socioeconômico, à medida que potencializa soluções científicas, técnicas e tecnológicas, com compromisso de estender benefícios à comunidade.

É importante reconhecermos os benefícios advindos dessa expansão, pois tivemos a oportunidade de trabalhar no campus da cidade de Pau dos Ferros, situado a aproximadamente $420 \mathrm{~km}$ da capital potiguar. Durante essa experiência profissional, pudemos lecionar em um campus que recebia alunos e alunas de ensino médio e de ensino superior de pelo menos 14 cidades circunvizinhas à cidade polo de Pau dos Ferros. Tivemos a oportunidade de conversar com alguns alunos que residiam em zonas rurais mais distantes, que viajavam cerca de duas horas para chegar ao campus. Não temos dúvida que a expansão do IFRN pode levar uma educação pública e com qualidade a esses alunos e alunas das regiões mais afastadas e desprovidas de recursos financeiros e educativos.

No entanto, é importante destacarmos também a nossa preocupação com algumas questões que perpassam a referida expansão, como a importância de um planejamento 
orçamentário governamental que corrobore com investimentos e com a manutenção dos IF'S, pois não adianta apenas criar novos campi e ampliar a cada ano o número de vagas ofertadas por eles, para atender aos acordos de metas estabelecidos por instituições financeiras internacionais. Consideramos como primordial a realização de um trabalho de acompanhamento sistemático e técnico com o intuito de prevenir o seu sucateamento, pois sabemos que quanto maior a infraestrutura, maiores serão os gastos e os cuidados para mantê-la com um bom padrão de qualidade no que tange a suas características, finalidades e objetivos.

Segundo o PPP (2012, p.17), o IFRN apresenta-se como uma instituição que tem a seguinte configuração:

\begin{abstract}
De organização pluricurricular, o IFRN oferece um ensino público, laico, gratuito e de qualidade. Oferta, nesse sentido, cursos em sintonia com a função social que desempenha, visando a consolidação e o fortalecimento dos arranjos produtivos, culturais e sociais locais. Apresenta, para tanto, um currículo organizado a partir de três eixos - ciência, trabalho, cultura e tecnologia - que atuam, de modo entrelaçado e intercomplementar, como princípios norteadores da prática educativa. O Instituto desenvolve a pesquisa e a extensão, na perspectiva de produção, socialização e difusão de conhecimentos. Estimula a produção cultural e realiza processos pedagógicos que levem à geração de trabalho e renda. Em um contexto mais amplo, a Instituição visa contribuir para as transformações da sociedade, visto que esses processos educacionais são construídos nas relações sociais.
\end{abstract}

Conscientes dessa perspectiva de organização pluricurricular, propomo-nos a refletir, nas linhas a seguir, sobre a inserção da Educação Física nesse processo de escolarização. Dessa forma, questionamos: como a Educação Física pode ser integrada a essa dimensão educacional, proposta pelos documentos e leis oficiais que regem o IFRN, transformando os seus pressupostos conceituais arraigados no esporte de rendimento em identificação histórica e social no âmbito institucional?

\title{
2 AS PERSPECTIVAS EDUCACIONAIS DA FUNÇÃO SOCIAL DA EDUCAÇÃO FÍSICA NO IFRN
}

Não pretendemos fazer aqui um resgate histórico sobre a inserção e a natureza do componente curricular Educação Física no IFRN, pois essa reflexão já foi feita por meio da dissertação de mestrado² intitulada "A configuração da Educação Física no Instituto Federal de Educação, Ciência e Tecnologia do Rio Grande do Norte - IFRN: contexto e perspectivas atuais". A referida dissertação deixou evidente a força, a influência política e social que o esporte tem no âmbito dos IF'S do Brasil, principalmente no IFRN. Souza Filho (2011, p.35), ao refletir sobre a influência do esporte sobre o componente curricular Educação Física, chega a afirmar que "no âmbito dos atuais Institutos Federais de educação, o esporte, ainda é o conteúdo norteador, para não dizer único, da prática pedagógica da Educação Física".

\footnotetext{
2 A referida dissertação foi defendida em abril de 2011 pelo autor Moysés Souza Filho, professor do IFRN campus Natal Zona Norte.
} 
Essa hegemonia do conteúdo esporte nas aulas de Educação Física no IFRN acompanha uma tendência nacional que foi amplamente difundida pela perspectiva esportivista denunciada pelo Coletivo de Autores (1992), dentre outras publicações da área, como também pelas diretrizes nacionais, como os PCN's de Educação Física do ensino médio - 2000 e os PCN's+ - 2002. De acordo com os PCN's (2000, p. 34), a influência do esporte é de tamanha dimensão em torno da Educação Física que se pode considerar "que temos não o esporte da escola, mas sim o esporte na escola. Isso indica a subordinação da Educação Física aos códigos/sentidos da instituição esportiva: esporte olímpico, sistema desportivo nacional e internacional". Passados praticamente quatorze anos desde a publicação dos PCN's do ensino médio, percebemos que essa realidade não mudou muito no ensino médio integrado do IFRN.

De acordo com a promulgação da Lei de Diretrizes e Bases da Educação Nacional - LDBEN no 9.394/96, de 20 de dezembro de 1996, a Educação Física passou a ser componente curricular obrigatório da educação básica, devendo ser integrada à proposta político-pedagógica da escola, assim como os demais componentes curriculares inseridos no contexto escolar. A promulgação desta Lei foi um marco para a Educação Física na escola, pois legitimou a ação dos profissionais que atuam nessa área.

No entanto, estabeleceu inevitavelmente um compromisso social maior dos diferentes componentes curriculares, pois sistematizou para cada nível de ensino algumas finalidades básicas a serem alcançadas. A referida lei estabeleceu as seguintes finalidades específicas para o ensino médio, na seção IV, em seu Art. 35

I - a consolidação e o aprofundamento dos conhecimentos adquiridos no ensino fundamental, possibilitando o prosseguimento de estudos; II - a preparação básica para o trabalho e a cidadania do educando, para continuar aprendendo, de modo a ser capaz de se adaptar com flexibilidade a novas condições de ocupação ou aperfeiçoamento posteriores; III - o aprimoramento do educando como pessoa humana, incluindo a formação ética e o desenvolvimento da autonomia intelectual e do pensamento crítico; IV - a compreensão dos fundamentos científico-tecnológicos dos processos produtivos, relacionando a teoria com a prática, no ensino de cada disciplina (BRASIL, 1996, p. 19).

A primeira finalidade atribuída ao ensino médio provocou inúmeras discussões no âmbito acadêmico da Educação Física, pois de que maneira esse componente curricular iria consolidar e aprofundar os conhecimentos adquiridos no ensino fundamental? Se historicamente suas ações pedagógicas foram desprovidas de sentido e significado para os alunos, como também, de uma base teórica e conceitual em todos os níveis de ensino. Nesse sentido, a Lei no 9.394/96 foi um marco para a Educação Física brasileira, pois apontou os caminhos iniciais para que os impasses pedagógicos pudessem ser superados tanto no plano legal quanto no plano da sua legitimação conceitual no espaço escolar.

Mesmo com todo o aparato teórico e metodológico produzido desde a promulgação da Lei 9.394/96, percebemos que ainda temos muito que fazer para que a Educação Física alcance um status de componente curricular fundamentado em uma teoria curricular propositiva que possa dimensioná-la no contexto do projeto político pedagógico institucional. Como reflexo dessa possibilidade de transformação, temos a proposta pedagógica da Educação Física para os cursos técnicos profissionalizantes do IFRN. 
Essa proposta, elaborada pelo coletivo docente, pode ser considerada como um avanço para a Educação Física no âmbito do IFRN, que, a partir do ano letivo de 2012, oficializou através dos trabalhos e do documento do PPP, o contexto do currículo integrado dos componentes da formação geral e profissional dos cursos técnicos de nível médio. Nesse sentido, a legitimação conceitual da Educação Física como componente curricular terá sua consolidação a partir dos relatos da prática pedagógica nos diversos campi e do acompanhamento das ações sistematizadas pela pró-reitoria de ensino do IFRN, no sentido de revisar periodicamente as bases filosóficas e epistemológicas do PPP e os pressupostos teóricos metodológicos das propostas dos diversos componentes curriculares dos cursos técnicos integrados. A base da produção de conhecimento encontra, na relação da práxis pedagógica, a dimensão contínua do sentido da prática pedagógica. Pensando assim, acreditamos que as ações coletivas fortalecem os pressupostos teóricometodológicos da proposta pedagógica da Educação Física do ensino médio integrado do IFRN, que estão assentados em três concepções pedagógicas, a saber: Abordagem Crítico-Emancipatória (KUNZ, 1991; 1994); Abordagem Crítico-Superadora (COLETIVO DE AUTORES, 1992) e Aulas abertas à experiência (HILDEBRANDT, 1986).

Diante deste cenario, podemos nos questionar como uma proposta pedagógica alicerçada em aportes conceituais tão distintos (materialismo histórico dialético - Crítico-Superadora, Fenomenologia - Crítico-Emancipatória, interesses e necessidades do aluno - Aulas abertas à experiência) pode coadunar com o Projeto Político Pedagógico do IFRN. Ao refletirmos sobre esse questionamento chegamos ao entendimento de que embora essas abordagens pedagógicas se distanciem em suas bases epistêmicas, elas compartilham de alguns aspectos comuns, como por exemplo, a formação humana integral, como também a valorização da cultura enquanto elemento que deve perpassar o ensino da Educação Física na escola, ressignificando assim as concepções de ensino tradicionalistas que consideram a Educação Física como um apêndice curricular, isto é, uma disciplina sem conhecimentos relevantes que tem a missão principal de fazer com que os educandos transpirem, aliviem as suas tensões e exercitem os seus corpos.

Nesse sentido, as abordagens teóricas que compõem o referido documento possibilitam aos professores de Educação Física desta instituição de ensino a trabalharem numa perspectiva ampliada em que os aspectos biológicos do corpo não devam ser considerados como os únicos aspectos a fazerem parte do seu arcabouço teórico e metodológico, mas que a construção do conhecimento em torno da cultura possa permear as suas práticas pedagógicas.

Assim, o trabalho de sistematização da elaboração da proposta foi uma ação coletiva dos docentes envolvidos com os objetivos, com os fundamentos, princípios e pressupostos norteadores do projeto político pedagógico institucional que envolve as concepções de ser humano, sociedade, cultura, educação, tecnologia, trabalho e educação, presentes na concepção de currículo integrado que foi implantado na nova proposta para a formação geral e profissional para os cursos técnicos integrados do IFRN. Nesse sentido, torna-se premente destacar que tal proposta pedagógica assemelha-se ao PPP com relação ao aspecto do inacabamento, apresentando-se como uma diretriz que precisa ser experimentada e reelaborada de acordo com as modificações de visão de mundo e sociedade que queremos acessar aos nossos educandos.

Após essa etapa, faz-se necessária a sistematização metodológica do processo de ensino e de aprendizagem, assim como a realização de fóruns de exposição e discussões que possam abrir espaço para a apresentação de relatos de experiência pedagógicas dos diversos campi do IFRN, revestindo de grande importância a Educação Física como componente curricular, visando à 
produção coletiva de conhecimento e formatando, assim, novas proposições teóricas e metodológicas com a publicação destas em artigos científicos, livros teóricos e metodológicos ou didáticos norteadores, comunicações orais em eventos acadêmicos, oficinas pedagógicas, o que pode vir a se tornar uma contribuição e uma referência para as proposições destinadas à Educação Física no nível médio de ensino integrado no âmbito regional.

Nesse sentido, a contribuição da Educação Física no âmbito do IFRN poderá se concretizar na medida em que o corpo docente, que desenvolve as ações pedagógicas do componente curricular, realize e socialize as experiências pedagógicas contextualizadas com a função social do IFRN na dimensão da formação integrada, considerando a cultura de movimento ${ }^{3}$ como o conjunto de conhecimentos relativos aos conteúdos temáticos predispostos pela proposta pedagógica. Além do mais, entendemos que a cultura de movimento não se limita ao espaço escolar, ela tem uma história que precede a entrada dos educandos(as) no espaço escolar e nele se consolida para a sequência dos estudos e da vida.

Nessa perspectiva, as ações pedagógicas da Educação Física no currículo integrado precisam ter sentido e significado para os educandos, pois a educação integral não se faz apenas com ações inter ou transdisciplinares; essa condição é uma das faces pedagógicas necessárias no ambiente escolar. A educação integral conscientiza os valores culturais associados à vida das pessoas e a adolescência é um tempo de mudanças corporais integrais, sendo o corpo aqui entendido em sua totalidade existencial. Corpo dotado de sensibilidade, de razão, de percepção, de criatividade, de afetividade, de sociabilidade, e a cultura de movimento pode promover todas essas dimensões pelas ações pedagógicas da Educação Física no ensino médio integrado.

\section{CONSIDERAÇÕES FINAIS}

Sabemos que temos vários desafios a serem vencidos para que possamos dar continuidade à consolidação pedagógica da Educação Física. No entanto, pelas possibilidades que hoje se apresentam para as condições didáticas e pedagógicas nos diversos campi do IFRN, e para que a proposta pedagógica da Educação Física não se torne mais um documento sem conexão com a prática pedagógica, o protagonismo docente passa a ter uma relevância fundamental para a identidade pedagógica da Educação Física para, assim, superarmos o paradoxo do "entre o não mais e o ainda não" ${ }^{4}$ da Educação Física escolar.

No sentido de aproximar esse protagonismo das discussões gestadas no âmbito institucional com a prática pedagógica dos professores de Educação Física do IFRN, podemos vislumbrar a defesa, em 2013, das dissertações de mestrado no Programa de Pós-graduação em Educação da UFRN, intituladas "Conhecimentos sobre o corpo: uma possibilidade de intervenção pedagógica nas aulas de Educação Física no ensino médio" e "A aplicação dos temas transversais

\footnotetext{
${ }^{3}$ Segundo Kunz (1998, p. 98), cultura de movimento são “todas as atividades do movimento humano, tanto no esporte como em atividades extra-esporte (ou no sentido amplo do esporte) e que pertençam ao mundo do 'se movimentar' humano, o que o homem por esse meio produz ou cria, de acordo com a sua conduta, seu comportamento e mesmo as resistências que oferecem a essas condutas e ações".

4 Entre o não mais e o ainda não é o paradoxo que González e Fensterseifer definem para a situação de legitimação pedagógica da Educação Física escolar. ENTRE O "NÃO MAIS" E O "AINDA NÃO": pensando saídas do não-lugar da educação física escolar. FERNANDO JAIME GONZÁLEZ e PAULO EVALDO FENSTERSEIFER. Cadernos de Formação RBCE, p. 9-24, set. 2009.

${ }^{5}$ Dissertação defendida pelo professor de Educação Física Alison Batista do campus Parnamirim.
} 
nas aulas de Educação Física no ensino médio integrado ${ }^{\prime \prime}$, como tentativas de aproximação da Educação Física da função social do IFRN preconizada pelos seus documentos oficiais. Esses trabalhos caracterizaram-se como pesquisas de intervenção pedagógica e configuraram-se em esforços teóricos e metodológicos na tentativa de romper com as perspectivas tradicionais de ensino da Educação Física, que ainda perduram nos Institutos Federais.

\section{REFERÊNCIAS}

1. BRASIL. Lei de Diretrizes e Bases da Educação Nacional - LDB. Casa Civil da Presidência da República. 1996. Brasília; DF.

2. Parâmetros curriculares nacionais do Ensino Médio - educação física. Brasília: MEC/SEF, 2000.

3. PCN'S + Ensino Médio. Orientações Educacionais Complementares aos Parâmetros Curriculares Nacionais. Linguagens, Códigos e suas Tecnologias. SEEB; Brasília; 2002.

4. Lei n. 11.892, de 29 de dezembro de 2008. In: DIÁRIO OFICIAL DA UNIÃO. 2008, Brasília; DF.

5. Diretrizes Curriculares para o Ensino Médio. CNE/SE/CEB; Brasília. 2012.

6. CABRAL NETO, Antônio. Avaliação do ensino superior no Brasil: as tensões entre emancipação e regulação. In: CHAVES, Lúcia Jacob Chaves, CABRAL NETO, Antônio e NASCIMENTO, Ilma Vieira (Orgs). Políticas para a educação superior no Brasil: velhos temas e novos desafios. São Paulo: Xamã, 2009.

7. COLETIVO DE AUTORES. Metodologia do Ensino de Educação Física. São Paulo: Cortez, 1992.

8. GONZÁLEZ, Fernando Jaime; FENSTERSEIFER, Paulo Evaldo. Cadernos de Formação RBCE, p. 924, set. 2009.

9. HILDEBRANDT, R. Concepções abertas no Ensino da Educação Física. Rio de Janeiro. Ao Livro técnico, 1986.

10. IFRN. Projeto Político-Pedagógico do IFRN: uma construção coletiva. Natal/RN, 2012.

11. Proposta de trabalho da disciplina de Educação Física para os cursos técnicos de nível médio integrado regular, EJA e subseqüente. Natal/RN, 2011.

12. .Organização Didática do IFRN. Natal/RN, 2012.

13. KUNZ, Elenor. Educação Física: Ensino e mudanças. ljuí, Ed. Unijuí, 1991.

14. Elenor. Transformação didático-pedagógica do esporte. 7ํeed., ljuí: Editora Unijuí, 1994.

15. SOUSA FILHO, Móyses de. A configuração da Educação Física no Instituto Federal de Educação, Ciência e Tecnologia do Rio Grande do Norte - IFRN: Contexto e perspectivas atuais. Natal (RN), 2011. Dissertação (Mestrado) - UFRN.

\footnotetext{
${ }^{6}$ Dissertação defendida pela professora de Educação Física Iracyara Assunção do campus São Gonçalo do Amarante.
} 